\title{
Total Synthesis of Kalimantacin A
}

Jonathan A. Davies, Freya M. Bull, Paul D. Walker, Angus N. M. Weir, Rob Lavigne, Joleen Masschelein, Thomas J. Simpson, Paul R. Race, Matthew P. Crump, and Christine L. Willis*

Cite This: Org. Lett. 2020, 22, 6349-6353

Read Online

ACCESS I

山l Metrics \& More

Article Recommendations

Supporting Information

ABSTRACT: The kalimantacins make up a family of hybrid polyketidenonribosomal peptide-derived natural products that display potent and selective antibiotic activity against multidrug resistant strains of Staphylococcus aureus. Herein, we report the first total synthesis of kalimantacin A, in which three fragments are prepared and then united via Sonogashira and amide couplings. The enantioselective synthetic approach is convergent, unlocking routes to further kalimantacins and analogues for structure-activity relationship studies and clinical evaluation.

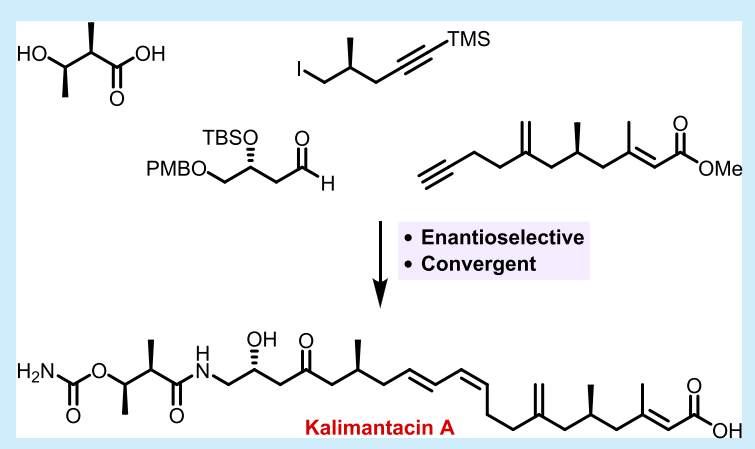

Scheme 1. (A) Selected Kalimantacin Natural Products and (B) Retrosynthetic Analysis of Kalimantacin Ester 4

A

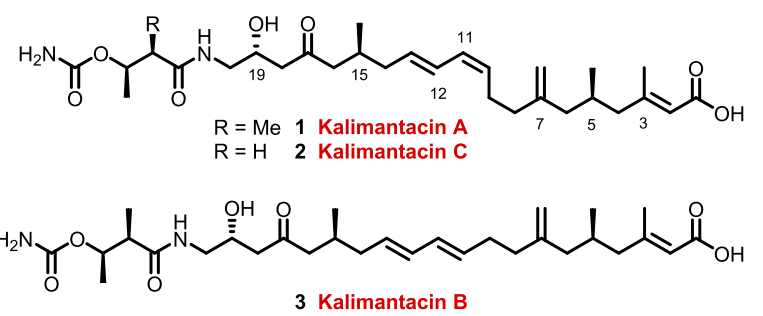

B

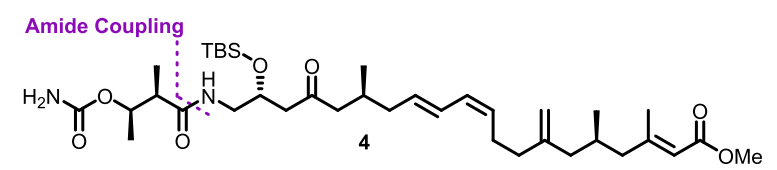

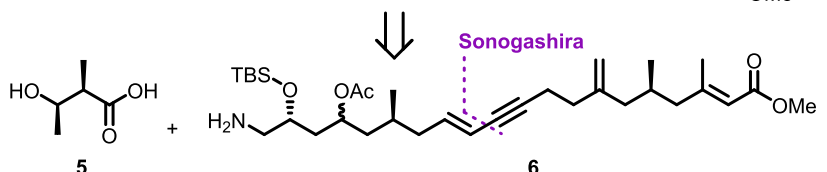

5<smiles>C#CCCC(=C)CC(C)C/C(C)=C/C(=O)OC</smiles>

$\mathrm{T}$ he kalimantacins $[\mathbf{1 - 3}($ Scheme 1A)] make up a family of bacterial metabolites of mixed polyketide-nonribosomal peptide synthase (PKS-NRPS) origin that display potent antibiotic activity. ${ }^{1}$ Originally isolated from a soil sample collected from the West Kalimantan region of Borneo, they are produced by several bacteria, including Pseudomonas fluorescens, and show high selectivity against multidrug resistant Staphylococcus species, including methicillin resistant Staphylococcus aureus (MRSA). ${ }^{2,3}$ The most active and abundant member is kalimantacin A $\mathbf{1}$ (also known as batumin), ${ }^{3}$ whose relative and absolute stereochemistry was determined in 2015 through a combination of degradation studies and fragment synthesis. ${ }^{4}$ Preliminary clinical research has indicated that topical application of kalimantacin $\mathrm{A}$ is highly effective at disrupting and preventing the formation of $S$. aureus biofilms. ${ }^{5}$

Another fascinating aspect of these natural products is their incorporation of $\beta$-branches, a structural feature present in many polyketides with important biological activities. ${ }^{6}$ Uniquely, the kalimantacins contain three different and sequential types of $\beta$-branches at C-3, C-5, and C-7, as well as an additional methyl group at $\mathrm{C}-15$. The biosynthetic mechanisms that control this remarkable selectivity have recently been investigated. $^{6}$

The antistaphylococcal activity of the kalimantacins derives from inhibition of FabI, an enoyl-acyl carrier protein reductase enzyme that plays an essential role in fatty acid biosynthesis.

Received: July 2, 2020

Published: August 10, 2020<smiles>CC(C)(C)OC[C@H](CC=O)O[13CH3]</smiles>

$+$<smiles>CC(C)C#CCC(C)CI</smiles>

10

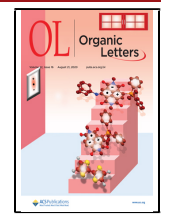


X-ray crystallography and molecular dynamics simulations have shown that the kalimantacin binding mode is unique, differing significantly from those of other FabI inhibitors. ${ }^{8}$ The stage is now set to gain further insights into the structureactivity relationships (SARs) of the kalimantacins, which will inspire future antistaphylococcal drug development. To realize this potential, access to a library of analogues is now urgently required. Herein, we describe the first total synthesis of kalimantacin A 1 via an enantioselective, flexible, and convergent approach.

In our retrosynthetic analysis, we anticipated that kalimantacin A could be prepared from protected ester 4 (Scheme 1B). From here, a late-stage amide coupling of $(2 R, 3 R)$-3-hydroxybutanoic acid 5 and amine 6 was proposed. The $(E, Z)$-diene was to be prepared via a Sonogashira coupling of vinyl iodide 7 and alkyne 8 , followed by stereoselective reduction of the enyne. It was envisaged that 7 could be assembled through lithiation of iodide $\mathbf{1 0}$ and reaction with aldehyde 9. This convergent approach was designed to be versatile and readily adaptable in terms of both chain length and functionality to synthesize analogues for SAR studies, as informed by X-ray crystallography and molecular dynamics simulations with FabI. Furthermore, the route was to be exploited for the preparation of putative biosynthetic intermediates to further probe the mechanisms of $\beta$-branch incorporation in polyketide biosynthesis.

To begin, it was important to establish if the proposed protecting groups of 4 could be readily removed in the final stages of the total synthesis. Thus, kalimantacin A 1 was isolated from cultures of $P$. fluorescens in titers of $65 \mathrm{mg} / \mathrm{L}$ using a procedure adapted from Mattheus et al. $^{3}$ The acid was methylated with $\mathrm{TMSCHN}_{2}$ to ester 11, and the 19-hydroxyl was protected as the TBS ether to give 4 in $81 \%$ yield over two steps (Scheme 2A). To ensure these protecting groups could be removed cleanly, silyl ether 4 was treated with TBAF giving

Scheme 2. Semisynthetic Studies of Kalimantacin A
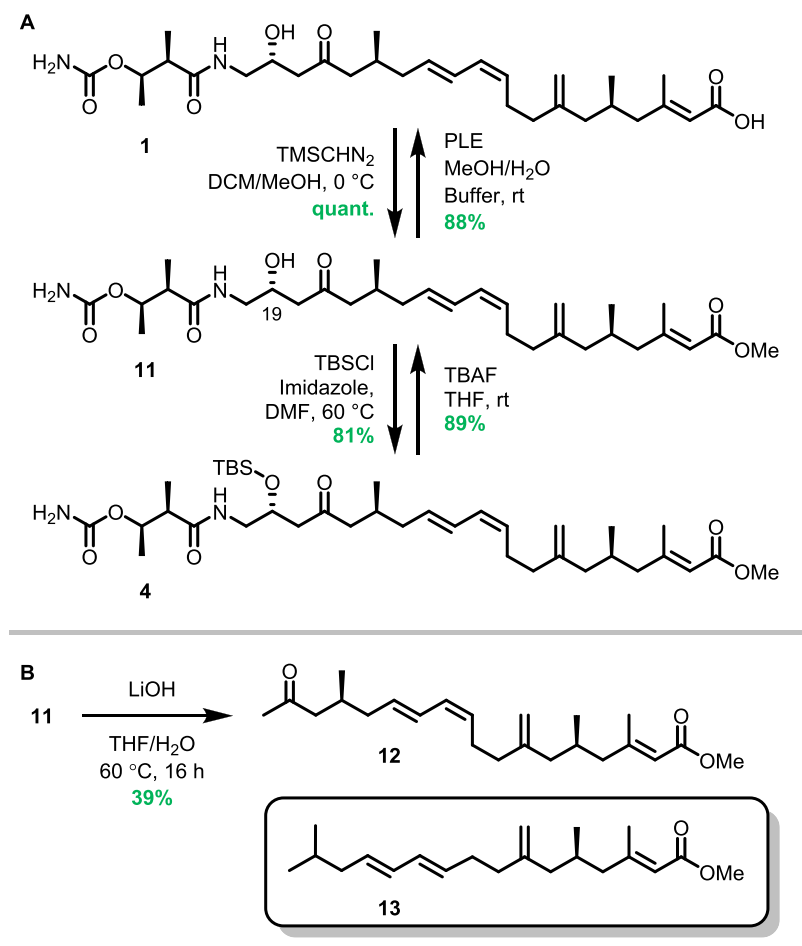

alcohol 11 in $89 \%$ yield. However, treatment of 11 with $\mathrm{LiOH}$ at room temperature returned only starting material and on heating to $60{ }^{\circ} \mathrm{C}$ gave methyl ketone 12 via retro-aldol fragmentation of the $\beta$-hydroxy ketone moiety (Scheme $2 \mathrm{~B}$ ). This compound is of interest for SAR studies as it closely resembles another natural product, 13, which was isolated from a freshwater sponge and also displays activity against Grampositive bacteria, including $S$. aureus. ${ }^{9}$ Hydrolysis of methyl ester 11 was achieved cleanly using porcine liver esterase (PLE), giving kalimantacin A 1 in $88 \%$ yield.

Turning to the total synthesis of kalimantacin A, vinyl iodide 7 (C-12-C-20) was assembled from two building blocks, aldehyde 9 and alkyl iodide 10, which were both prepared on a multigram scale using previously reported procedures (see the Supporting Information). Aldehyde 9 was synthesized in five steps and $68 \%$ overall yield starting from the chiral epoxide $(S)-(-)$-glycidol. ${ }^{10}$ Iodide 10 was prepared in three steps and $45 \%$ yield from a commercially available propionylated Evans auxiliary. ${ }^{11}$

Lithiation of iodide $\mathbf{1 0}$ using $t \mathrm{BuLi}$ was required for the coupling with aldehyde 9. It was found that only poor conversion to $\mathbf{1 5}$ was observed at low temperatures, with warming to $0{ }^{\circ} \mathrm{C}$ required to obtain full consumption of aldehyde 9. However, at temperatures above approximately $-20{ }^{\circ} \mathrm{C}$, the alkyl lithium cyclized to give cyclobutylidene 14 (which was trapped by an electrophile), meaning careful temperature control was required (Scheme 3A). ${ }^{12-14}$ Addi-

Scheme 3. (A) Lithiation and Rearrangement of Iodide 10 and (B) Synthesis of Vinyl Iodide 7 (C-12-C-20)
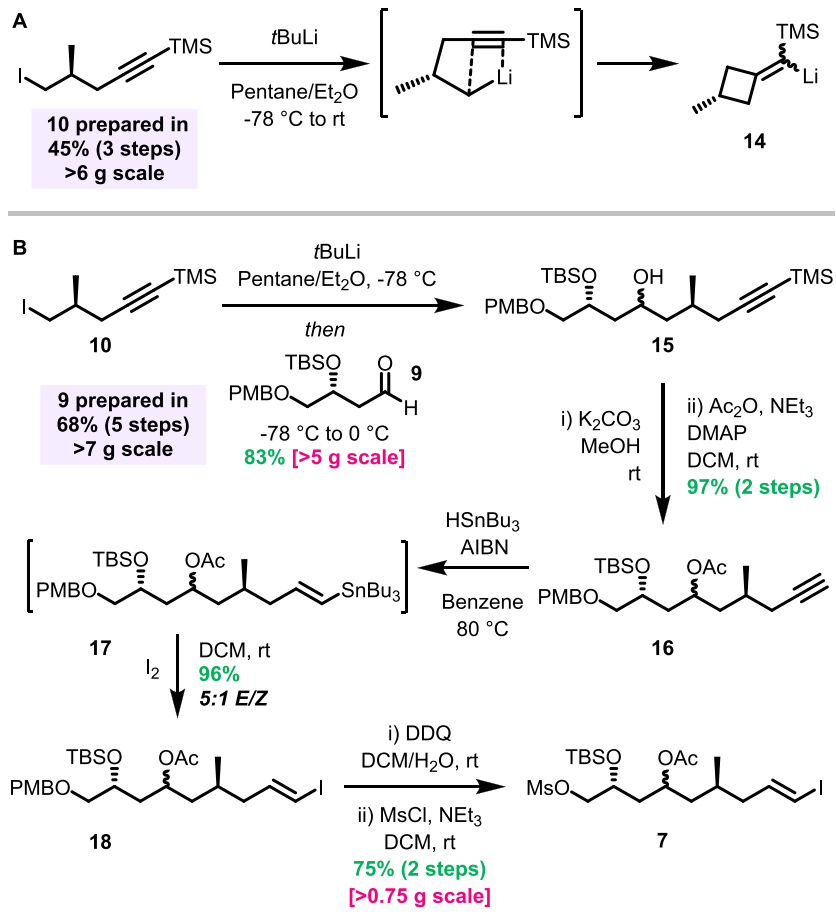

tionally, if an overly large excess of $t \mathrm{BuLi}$ was employed ( $>1.5$ equiv with respect to iodide 10), then a secondary alcohol was formed via addition to aldehyde 9. Following optimization, desired alcohol 15 was isolated as a mixture of diastereomers in $83 \%$ yield and the coupling was successful on a multigram scale (Scheme 3B). Removal of the TMS group using $\mathrm{K}_{2} \mathrm{CO}_{3}$ in $\mathrm{MeOH}$ followed by acetylation gave ester 16. The (E)-vinyl 
iodide was installed through hydrostannation of the alkyne to give 17 , followed by in situ treatment with iodine to give 18 . Deprotection was undertaken at this stage to give the corresponding alcohol, as DDQ was found to give a complex mixture post-Sonogashira coupling. Finally, the alcohol was transformed to mesylate 7 in $75 \%$ yield over two steps.

Preparation of alkyne 8 (C-1-C-11) was based upon our previous work used in the structural assignment of kalimantacin $\mathrm{A}$ in which iodide $\mathbf{1 9}$ was used as a synthetic intermediate (Scheme 4). ${ }^{4} \mathbf{1 9}$ was subjected to lithium-

Scheme 4. Synthesis of Alkyne 8 (C-1-C-11)

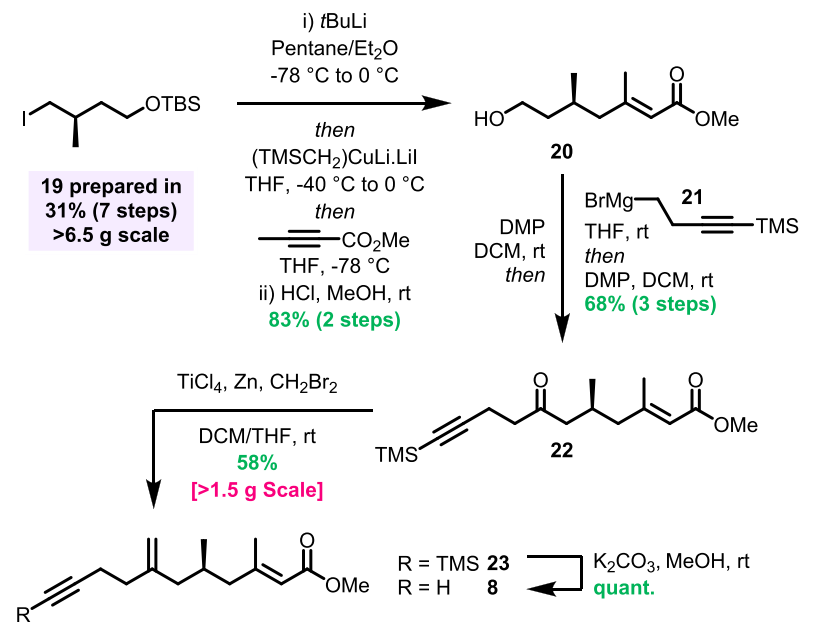

halogen exchange with $t \mathrm{BuLi}$ and then added to a freshly prepared solution of trimethylsilylmethylcopper to generate a mixed cuprate species in which the trimethylsilylmethyl group acts as an activating but nontransferable ligand. ${ }^{15,16}$ Conjugate addition to methyl but-2-ynoate proceeded with complete stereocontrol for the $(E)$-alkene, and then the TBS group was cleaved under acidic conditions to liberate alcohol 20 in $83 \%$ yield over two steps. Oxidation was undertaken using DessMartin periodinane (DMP) to provide the aldehyde, which was treated with Grignard reagent 21, formed from the corresponding bromide. ${ }^{17}$ The resulting mixture of alcohols was again oxidized using DMP to give ketone 22 as a single enantiomer in $68 \%$ yield over three steps. The next stage was the introduction of the exo-methylene moiety that had been undertaken previously using Tour methylenation conditions $\left(\mathrm{Cp}_{2} \mathrm{ZrCl}_{2}, \mathrm{CH}_{2} \mathrm{I}_{2}\right.$, and $\left.\mathrm{Zn}\right){ }^{4,18}$ While this was successful, the reaction was capricious giving variable yields. Instead, it was found that a Lombardo methylenation $\left(\mathrm{TiCl}_{4}, \mathrm{CH}_{2} \mathrm{Br}_{2}\right.$, and $\mathrm{Zn})^{19}$ was more robust and reproducible, providing 23 in $58 \%$ yield on a gram scale. Finally, deprotection was undertaken using $\mathrm{K}_{2} \mathrm{CO}_{3}$ in $\mathrm{MeOH}$ to give alkyne 8 .

The Sonogashira coupling of vinyl iodide 7 and alkyne 8 proceeded smoothly to give enyne 24 in $88 \%$ yield, thus completing the construction of the C-1-C-20 backbone of kalimantacin A 1 (Scheme 5A). The next step of the synthesis required conversion of mesylate 24 to azide $\mathbf{2 5}$. Maeda and coworkers had reported that the steric bulk of a TBS group hindered nucleophilic substitutions in similarly protected 1,2diols. ${ }^{20}$ However, heating mesylate 24 with $\mathrm{NaN}_{3}$ gave azide 25 in $85 \%$ yield. Reduction of azide 25 to amine 6 was achieved using a Staudinger reaction employing $\mathrm{PPh}_{3}$ in a mixture of THF and $\mathrm{H}_{2} \mathrm{O}$. This reaction required very careful degassing, as in the presence of air, rather than the required hydrolysis of intermediate iminophosphorane 28 , an aza-Wittig

Scheme 5. (A) Completing the Total Synthesis of Kalimantacin A and (B) Formation of Urea 30

A<smiles>C#CCCC(=C)C[C@H]([18OH])C/C(C)=C/C(=O)OC</smiles>

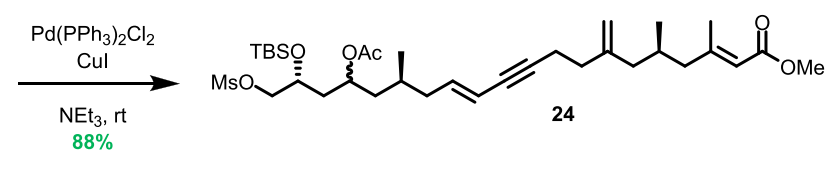
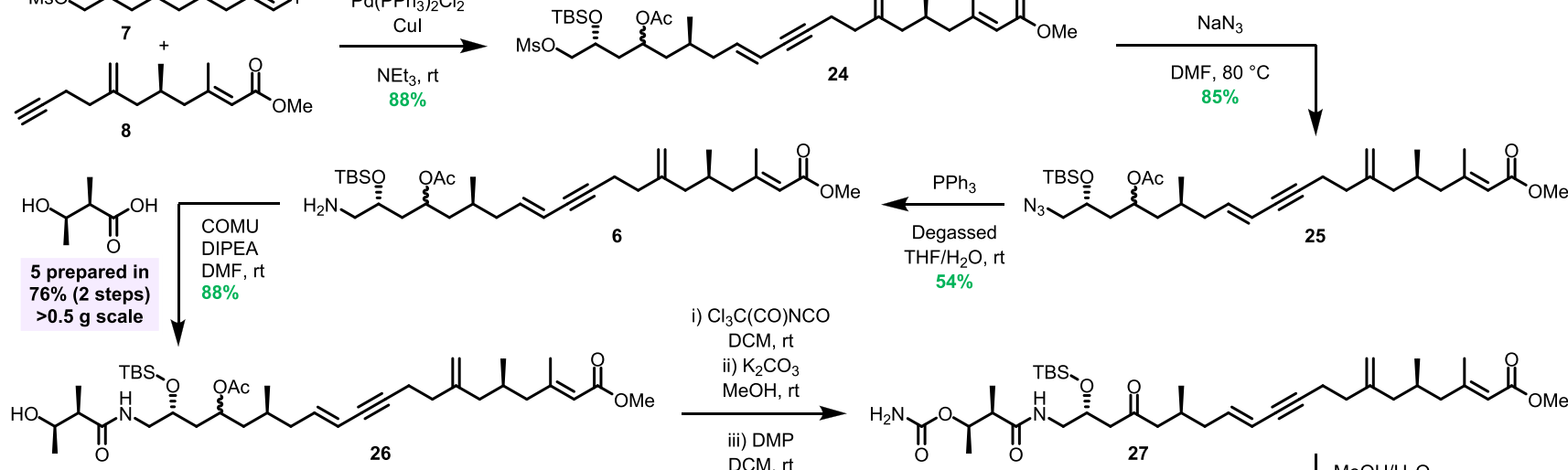

i) $\mathrm{Cl}_{3} \mathrm{C}(\mathrm{CO}) \mathrm{NCO}$

$\mathrm{DCM}, \mathrm{rt}$
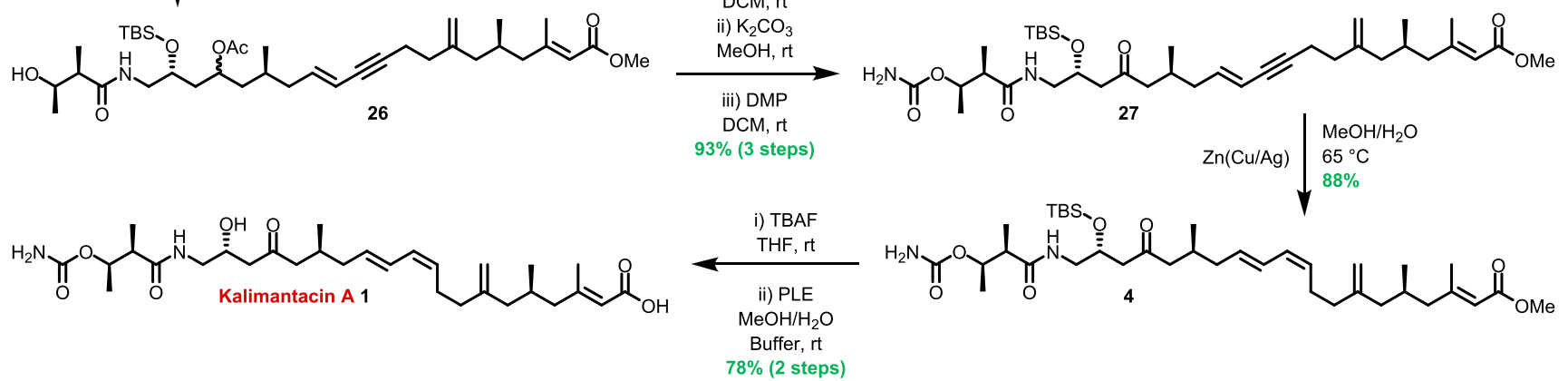

$78 \%$ (2 steps)
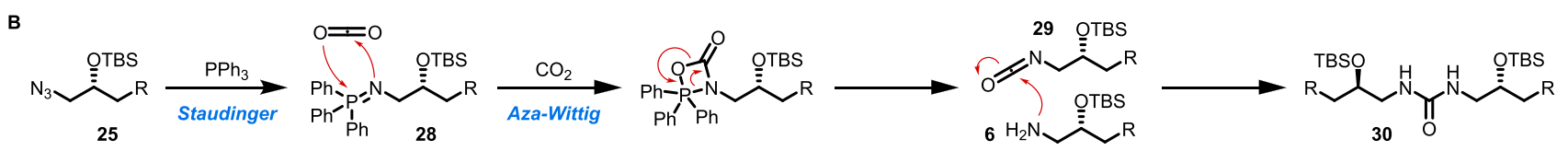
reaction with carbon dioxide occurred to give isocyanate 29, which further reacted to give dimeric urea species 30 (Scheme $5 B) .^{21,22}$

The final fragment, acid 5, was prepared in two steps and $76 \%$ yield from ethyl (R)-3-hydroxybutanoate (see the Supporting Information). Coupling of hydroxy acid $\mathbf{5}$ and amine 6 was undertaken with no protection of the alcohol, thus obviating the need for further protecting group manipulations. Using COMU and $i \mathrm{Pr}_{2} \mathrm{NEt}$, hydroxy-amide $\mathbf{2 6}$ was isolated in $88 \%$ yield. Carbamoylation of 26 using trichloroacetyl isocyanate was followed by concomitant hydrolysis of both acetates with $\mathrm{K}_{2} \mathrm{CO}_{3}$ in $\mathrm{MeOH}$. Oxidation of the resultant alcohol with DMP provided ketone $\mathbf{2 7}$ in $93 \%$ yield over three steps.

The final key step of the total synthesis was the selective reduction of $(E)$-enyne 27 to generate the required $(E, Z)$ diene 4. In this case, commonly used hydrogenation with a poisoned palladium catalyst was avoided due to concerns of achieving the required chemoselectivity. Instead, 27 was treated with zinc activated with copper and silver, which gave the desired $(E, Z)$-diene 4 in $88 \%$ yield as a single isomer as determined by ${ }^{1} \mathrm{H}$ NMR spectroscopy $(J=15$ and $11 \mathrm{~Hz}$, respectively). ${ }^{23}$ The optical rotation of diene 4 prepared by total synthesis was in excellent agreement with the reference material obtained via protection of kalimantacin A 1 isolated from cultures of $P$. fluorescens (Scheme 2). Finally, following the previously established deprotection and ester hydrolysis protocols (Scheme 2), we completed the first total synthesis of kalimantacin A 1. The NMR spectral data and HPLC retention time were in accord with those of an authentic sample of the natural product (see the Supporting Information).

In conclusion, herein we have reported the first total synthesis of the PKS-NRPS-derived antibiotic natural product kalimantacin A 1. The enantioselective and convergent approach unites three fragments via Sonogashira and amide couplings. This flexible synthetic strategy, combined with recent insights into the binding of kalimantacin to $\mathrm{FabI}^{8}{ }^{8}$ will enable SAR studies to be undertaken, thus paving the way for the design of future selective antistaphylococcal drugs and their development for clinical assessment. Additionally, this route will be adapted for the synthesis of putative biosynthetic intermediates to further probe the mechanisms of $\beta$-branch incorporation in kalimantacin biosynthesis.

\section{ASSOCIATED CONTENT}

\section{SI Supporting Information}

The Supporting Information is available free of charge at https://pubs.acs.org/doi/10.1021/acs.orglett.0c02190.

Experimental procedures and spectral data for all new compounds (PDF)

\section{AUTHOR INFORMATION}

\section{Corresponding Author}

Christine L. Willis - School of Chemistry, University of Bristol, Bristol BS8 1TS, United Kingdom; 다이.org/0000-00023919-3642; Email: chris.willis@bristol.ac.uk

\section{Authors}

Jonathan A. Davies - School of Chemistry, University of Bristol, Bristol BS8 1TS, United Kingdom

Freya M. Bull - School of Chemistry, University of Bristol, Bristol BS8 1TS, United Kingdom
Paul D. Walker - School of Chemistry, University of Bristol, Bristol BS8 1TS, United Kingdom

Angus N. M. Weir - School of Chemistry, University of Bristol, Bristol BS8 1TS, United Kingdom

Rob Lavigne - Laboratory of Gene Technology, KU Leuven, 3001 Leuven, Belgium

Joleen Masschelein - Laboratory for Biomolecular Discovery and Engineering, KU Leuven, 3001 Leuven, Belgium; VIB-KU Leuven Center for Microbiology, Flanders Institute for Biotechnology, 3001 Leuven, Belgium

Thomas J. Simpson - School of Chemistry, University of Bristol, Bristol BS8 1TS, United Kingdom

Paul R. Race - School of Biochemistry, University of Bristol, Bristol BS8 1TD, United Kingdom; 이이.org/0000-00030184-5630

Matthew P. Crump - School of Chemistry, University of Bristol, Bristol BS8 1TS, United Kingdom; 이이이.org/0000-00027868-5818

Complete contact information is available at:

https://pubs.acs.org/10.1021/acs.orglett.0c02190

\section{Notes}

The authors declare no competing financial interest.

\section{ACKNOWLEDGMENTS}

Financial support for this work was provided by the BBSRC and EPSRC through the Bristol Centre for Synthetic Biology (BB/L01386X/1), Bristol Chemical Synthesis Centre for Doctoral Training for J.A.D. and P.D.W. (EP/L015366/1), and doctoral training grants for F.M.B. and A.N.M.W.

\section{REFERENCES}

(1) Tokunaga, T.; Kamigiri, K.; Orita, M.; Nishikawa, T.; Shimizu, M.; Kaniwa, H. J. Antibiot. 1996, 49, 140.

(2) Kamigiri, K.; Suzuki, Y.; Shibazaki, M.; Morioka, M.; Suzuki, K.; Tokunaga, T.; Setiawan, B.; Rantiatmodjo, R. M. J. Antibiot. 1996, 49, 136.

(3) Mattheus, W.; Gao, L.-J.; Herdewijn, P.; Landuyt, B.; Verhaegen, J.; Masschelein, J.; Volckaert, G.; Lavigne, R. Chem. Biol. 2010, 17, 149.

(4) Thistlethwaite, I. R. G.; Bull, F. M.; Cui, C.; Walker, P. D.; Gao, S.-S.; Wang, L.; Song, Z.; Masschelein, J.; Lavigne, R.; Crump, M. P.; Race, P. R.; Simpson, T. J.; Willis, C. L. Chem. Sci. 2017, 8, 6196.

(5) Churkina, L. N.; Bidnenko, S. I.; Lopes dos Santos Santiago, G.; Vaneechoutte, M.; Avdeeva, L. V.; Lutko, O. B.; Oserjanskaja, N. M. BMC Res. Notes 2012, 5, 374.

(6) Walker, P. D.; Williams, C.; Weir, A. N. M.; Wang, L.; Crosby, J.; Race, P. R.; Simpson, T. J.; Willis, C. L.; Crump, M. P. Angew. Chem., Int. Ed. 2019, 58, 12446.

(7) Mattheus, W.; Masschelein, J.; Gao, L.-J.; Herdewijn, P.; Landuyt, B.; Volckaert, G.; Lavigne, R. Chem. Biol. 2010, 17, 1067.

(8) Fage, C. D.; Lathouwers, T.; Vanmeert, M.; Gao, L.-J.; Vrancken, K.; Lammens, E.-M.; Weir, A. N. M.; Degroote, R.; Cuppens, H.; Kosol, S.; Simpson, T. J.; Crump, M. P.; Willis, C. L.; Herdewijn, P.; Lescrinier, E.; Lavigne, R.; Anné, J.; Masschelein, J. Angew. Chem., Int. Ed. 2020, 59, 10549.

(9) Rezanka, T.; Dembitsky, V. M. J. Nat. Prod. 2002, 65, 709.

(10) Bonini, C.; Chiummiento, L.; Videtta, V.; Colobert, F.; Solladié, G. Synlett 2006, 2006, 2427.

(11) Forsyth, C. J.; Xu, J.; Nguyen, S. T.; Samdal, I. A.; Briggs, L. R.; Rundberget, T.; Sandvik, M.; Miles, C. O. J. Am. Chem. Soc. 2006, $128,15114$.

(12) Baldwin, J. E. J. Chem. Soc., Chem. Commun. 1976, 734.

(13) Gilmore, K.; Alabugin, I. V. Chem. Rev. 2011, 111, 6513.

(14) Bailey, W. F.; Ovaska, T. V. J. Am. Chem. Soc. 1993, 115, 3080. 
(15) Bertz, S. H.; Eriksson, M.; Miao, G.; Snyder, J. P. J. Am. Chem. Soc. 1996, 118, 10906.

(16) Dymock, B. W.; Kocienski, P. J.; Pons, J.-M. Synthesis 1998, 1998, 1655.

(17) Kolundžić, F.; Murali, A.; Pérez-Galán, P.; Bauer, J. O.; Strohmann, C.; Kumar, K.; Waldmann, H. Angew. Chem., Int. Ed. 2014, 53, 8122.

(18) Tour, J. M.; Bedworth, P. V.; Wu, R. Tetrahedron Lett. 1989, 30, 3927.

(19) Lombardo, L. Tetrahedron Lett. 1982, 23, 4293.

(20) Maeda, K.; Yamamoto, Y.; Tomimoto, K.; Mase, T. Synlett 2001, 2001, 1808.

(21) Carnaroglio, D.; Martina, K.; Palmisano, G.; Penoni, A.; Domini, C.; Cravotto, G. Beilstein J. Org. Chem. 2013, 9, 2378.

(22) Yagodkin, A.; Löschcke, K.; Weisell, J.; Azhayev, A. Tetrahedron 2010, 66, 2210.

(23) Boland, W.; Schroer, N.; Sieler, C.; Feigel, M. Helv. Chim. Acta $1987,70,1025$. 